\title{
Two-Domain Estimation of Hydraulic Properties in Macropore Soils
}

\author{
C. Chen, * D. M. Thomas, R. E. Green, and R. J. Wagenet
}

\begin{abstract}
Estimation of hydraulic properties of soils having macropores is dificult, yet very important for describing soil-water thow dyaamics. Conventional approaches of defining macroporosity based on pore size may not be generally successful in quantitatively relating macroporosity to the dynamics of water now. A definition of mecroporosity based on water flux at different degrees of water saturation can be expected to be more useful. This study attempted to quantily the functional macroporosity of field soil from in situ measurements of water content, $\theta(z, t)$, during drainage of an initially field-saturated soil. The soil was assumed to be a two-domain water how system comprised of macropores, which dominate the earty drainage process, and the matrix pore space, which is responsible for draiange eccurrias after macropores are emptied. The unit hydraulic gradient approach of calculating hydraulic conductivity was extended and applied to the two-domain system. Field-measured data for a well-draibed Wahiown soil (clayey, knolinitic, isohyperthermic Tropeptic Eutrustox) in Hawaii were used to test the approach. The partitioned hydraulic coaductivities obtained for the two domains appeared gualitatively realiotle, and when summed, resulted in a composite saturated condectivity which was close to that meesured by the in situ inotantanecus profike method. In addition, the macroporosities obtained trom drainage cal. culations for three soil depths were very simblar to those obtained from water retention measurements on undisturbed soll cores from the same field site. The proposed approach thus appears to be a promising methed for evaluating hydraulic properties for a well-drained soil profile containing macropores.
\end{abstract}

\begin{abstract}
Classical aPPROACHES of modeling preferential water flow in soils containing macropores (cracks, worm holes, and root channels) have traditionally encountered large deviations from field measurement because of the differences between tlow in the soil matrix and macropores. More recently, two-domain analysis of water flow and chemical transport in unsaturated soils containing macropores has been suggested by a

C. Chen and D.M. Thomas, School of Ocean and Earth Science and Technology, Hawaii Institute of Geophysics, Univ. of Hawaii, 2525 Correa Rd., Honolulu, HI 96822; R.E. Green, Dep. of Agronomy and Soil Science, Univ. of Hawaii, Honolulu, HI 96822; and R.J. Wagenet. Dep. of Soil, Plant and Atmospheric Sciences, Cornell Univ. Ithaca, NY 14853. School of Ocean and Earth Science and Technology Contribution no. 3138. Received 18 July 1991 . "Corresponding author.
\end{abstract}

Published in Soil Sci. Soc. Am. J. 57:680-686 (1993). number of investigators (Bouma et al., 1979; Beven and Germann, 1982; Chen and Wagenet, 1992a,b). In the two-domain conceptualization, the domain of the soil matrix represents micropores that behave as a homogeneous medium, and the domain of the soil macropore represents the soil porosity component that conducts water faster than the matrix domain. Absence of a method to estimate the hydraulic conductivities for both matrix and macropore domains, as well as the total macroporosity, however, limits the application of the two-domain approach. We propose a method for obtaining matrix and macropore conductivities from field measurements of water content redistribution with time after initial saturation of the profile.

Macropores can be defined in different ways: by size (e.g., 30-3000 $\mathrm{\mu m}$ in diameter); by tension at which they are all emptied of water (e.g., $5 \mathrm{kPa}$ ); by volume fraction (e.g., $0.001-0.05)$; or by infiltration rate (e.g., 1-10 $\mathrm{mm} \mathrm{h}^{-1}$ ) (Hall et al., 1977; Beven and Germann, 1982; White, 1985b; Chen and Wagenet, 1992a). The numerical values defining macropores with any of the above properties are not exact but are relative to the associated matrix properties (White, 1985b; Chen and Wagenet, 1992a). Therefore, there is no universal definition of macropores to separate this class of pores from all others. Commonly, researchers address soil heterogeneity in relation to macropores from one of two perspectives: hydraulic effectiveness and significance, or structural composition (White, 1985b). This study emphasized the hydraulic effectiveness and significance of two-domain properties in relation to soil drainage process. The theoretical basis was derived from the unit-hydraulic-gradient method developed by Libardi et al. (1980) to estimate hydraulic conductivity in the field. We assumed that water redistribution after initial saturation of the profile is only in response to the gravitational field and that the hydraulic conductivity of the matrix is an exponential or a power function of soil water content. Under an initial condition of uniform saturated water content in the soil profile, the Richards equation can be simplified to estimate the hydraulic conductivity when water redistribution can be mon- 
itored with time. The process of water redistribution and water drainage was recognized as being initially dominated by macropores, continued by a mixed stage before macropores are empty and after the matrix starts draining, and followed by the slower process of matrix drainage only. Characterization of the beginning stages of drainage can be used to calculate the hydraulic conductivity for the macropore domain; the last matrix-drying stage can be used to obtain the hydraulic conductivity for the matrix domain. The mixed stage is not valid, and may create large errors for the analyses of either the macropore or matrix domain.

Several models have been proposed for two-domain systems. Van Genuchten and Wierenga (1976) divided the two domains of soil water into mobile and immobile phases that depend on soil properties and flow rate. Addiscott et al. (1978) proposed a similar conceptual approach to describe field movement of $\mathrm{Cl}^{-}$and $\mathrm{NO}_{3}^{-}$. They utilized an empirical method that partitions the incoming water between mobile and retained water and a mixing process between the two, with subsequent transport between defined layers of the soil profile. Hoogmoed and Bouma (1980) assumed that the matrix and the macropores are separate domains with horizontal exchange and proposed a twodomain model for clay soil to simulate flow situations. To predict $\mathrm{NO}_{3}^{-}$leaching through an unsaturated macropore soil, White (1985a) developed an approach that assumed a time-variable volume of water formed by resident water mixing proportionally with infiltrating water, and simultaneous changes in chemical storage within the soil matrix. Beven and Germann (1982) and Germann and Beven (1985) applied a kinematic wave approach to describe vertical water flow along macropores that included a sink function for water absorbance into the soil matrix domain. Chen and Wagenet (1992a,b) applied filter theory to simplify the Richards equation and the convection-dispersion equation to obtain a set of analytical solutions for the matrix and macropore domains.

In addition to the two-domain approach, other models have been proposed. A multidomain approach was applied to macropore flow by grouping pore sizes (Steenhuis et al., 1987; Steenhuis and Parlange, 1988), and Luxmoore (1981) suggested that a mesopore class can be used to represent the pore size range between macropore and micropore. Jury (1982) and Jury et al. (1989) developed a stochastic transfer function to estimate the influence of soil heterogeneity on solute transport.

One approach for a two-domain simulation (Chen and Wagenet, 1992a,b) depends on the hydraulic properties of both the matrix and the macropores. The hydraulic conductivity of both the matrix and the macropore domains is defined relative to the total soil cross-section so that the total saturated hydraulic conductivity, $K_{\mathrm{s}}\left(\mathrm{mm} \mathrm{d}^{-1}\right)$, is

$$
K_{\mathrm{s}}=K_{\mathrm{sh}}+K_{\mathrm{sm}}
$$

where $K_{\text {sh }}\left(\mathrm{mm} \mathrm{d}^{-1}\right)$ is the matrix saturated hydraulic conductivity and $K_{\mathrm{sm}}\left(\mathrm{mm} \mathrm{\textrm {d } ^ { - 1 }}\right)$ is the macropore saturated hydraulic conductivity. When $\theta \leq \theta_{\text {sh, }}$ Camp- bell's (1974) equation describes the relationship between matrix hydraulic conductivity, $K_{\mathrm{h}}\left(\mathrm{mm} \mathrm{d}^{-1}\right)$, and matrix water content:

$$
K_{\mathrm{h}}(\theta)=K_{\mathrm{sh}}\left(\frac{\theta}{\theta_{\mathrm{sh}}}\right)^{2 b+3}
$$

where $\theta_{\mathrm{sh}}\left(\mathrm{cm}^{3} \mathrm{~cm}^{-3}\right)$ is the saturated water content of the matrix domain and also a threshold water content above which macropore flow is initiated, and $\theta$ $\left(\mathrm{cm}^{3} \mathrm{~cm}^{-3}\right)$ is the water content when $\theta \leq \theta_{\mathrm{sh}}$, or the matrix water content, and $b$ is a constant (dimensionless). Since macropores form a relatively small proportion of the total porosity, it can be assumed that a linear function will approximate the relationship between macropore hydraulic conductivity, $K_{\mathrm{m}}\left(\mathrm{mm} \mathrm{d}^{-1}\right)$, and water-filled macroporosity, $p\left(\mathrm{~cm}^{3} \mathrm{~cm}^{-3}\right)$. When $\theta \geq \theta_{\operatorname{sh}}$, for the macropore domain:

$$
K_{\mathrm{m}}(p)=K_{\mathrm{sm}} \frac{\theta-\theta_{\mathrm{sh}}}{\theta_{\mathrm{s}}-\theta_{\mathrm{sh}}}=K_{\mathrm{sm}} \frac{p}{p_{\mathrm{m}}},
$$

where $\theta_{3}\left(\mathrm{~cm}^{3} \mathrm{~cm}^{-3}\right)$ is the saturated water content, referring to the total soil volume, including both micropores and macropores, and $p_{\mathrm{m}}\left(\mathrm{cm}^{3} \mathrm{~cm}^{-3}\right)$ is the total macroporosity. A method to estimate saturated hydraulic conductivities for both the matrix and the macropore domains is described below.

\section{THEORY}

Consistent with Libardi et al. (1980) a soil profile is assumed to be initially saturated $(t=0)$ when, for $t>0$, the flux at the soil surface is zero with the soil water redistributing and draining when there is no evaporation. Application of the proposed method is based on the theory that pores are filled and drained in order by size, the smaller pores being filled first and drained last. This requires an additional assumption that the drainage process initially is dominated by macropores, progresses to mixed drainage from both macropore and matrix domains, and finally evolves to matrix drainage only. The mixed stage of the drainage process corresponds to the declining stages of macropore flow when matrix flow becomes a significant portion of the total drainage. Calculation of the hydraulic parameters from the $\theta(t)$ measurements during this interval does not yield an accurate representation of either the matrix or macropore flow. from

The matrix saturated water content $\left(\theta_{s n}\right)$ can be calculated

$$
\theta_{\mathrm{sh}}=\theta_{\mathrm{s}}-p_{\mathrm{m}},
$$

where $\theta_{3}$ is estimated either from field measurement or by setting the total porosity $\epsilon=\left(1-\rho_{v} / \rho_{p}\right)\left(\mathrm{cm}^{3} \mathrm{~cm}^{-3}\right)$, where $P_{b}$ is the soil bulk density measured from the soil $\left(\mathrm{g} \mathrm{cm}^{-3}\right)$ and $\rho_{\mathrm{p}}$ is the soil particle density measured from the soil or estimated to be $2.65 \mathrm{~g} \mathrm{~cm}^{-3}$. The total obtainable macroporosity, $p_{m}$, is described below.

The continuity equation, which incorporates Darcy's law (where $q$ is the vertical flux) in the development of the Richards equation, is:

$$
\frac{\partial \theta}{\partial t}=-\frac{\partial q}{\partial z}
$$

in which both $q$ and $z$ are positive in the downward direction. 
By integrating Eq. [5] on both sides from the soil surface $(z$ $=0$ ) 10 depth $z$ from time 0 to $t$, and letting $\theta^{*}$ be the average value of water content from depth 0 to $z$, we obtain as did Libardi et al. (1980):

$$
\begin{aligned}
& \int_{0}^{z} \frac{\partial \theta}{\partial t} \mathrm{~d} z=-\int_{0}^{z} \frac{\partial q}{\partial z} \mathrm{~d} z \\
& z \frac{\mathrm{d} \theta^{*}}{\mathrm{~d} t}=\left.q\right|_{z=0}-\left.q\right|_{z=z}
\end{aligned}
$$

For our boundary condition that $q$ at the soil surface is zero when $t>0$, Eq. [7] simplifies to:

$$
z \frac{\mathrm{d} \theta^{*}}{\mathrm{~d} t}=-\left.q\right|_{z=z} \cdot
$$

Because the hydraulic gradient of the soil profile is approximately unity during drainage stages so that $\partial H / \partial z=-1$, water flux $q$ at depth $z$ is then equal to the soil hydraulic conductivity $K$ at depth $z$. The hydraulic head, $H$, has the same dimension as depth $z$. Whether this $K$ represents hydraulic conductivity for the matrix or macropore domain is dependent on the drainage stage in the soil profile. Furthermore, the average soil water content from $z=0$ to $z=z$ is assumed to have the following relationship with the soil water content at a particular depth $z$ :

$$
\theta^{*}=\alpha \theta_{z}+\beta
$$

where $\alpha$ and $\beta$ are constants, which can be determined by regression of $\theta^{*}$ against $\theta_{z}$ of measured data at different depths in the profile.

Combining Eq. [8] and [9] under the unit hydraulic gradient in the soil profile gives a general solution below. Note that $\beta$ is eliminated by differentiation.

$$
\alpha z \frac{\mathrm{d} \theta}{\mathrm{d} t}=-K
$$

\section{The Macropore Domain}

A solution for the macropore domain was developed for the initially saturated profile using $\partial H / \partial z=-1$ for small time, $t$ $\leq t_{\mathrm{m}}$, where $t_{\mathrm{m}}$ is a data breakpoint within the drainage stage of macropore flow only (i.e., before matrix drainage starts). The value of $t_{\mathrm{m}}$ can be estimated by inspecting the plot $\operatorname{of} \ln (\theta)$ vs. In(t) for all the data, and verified by using the obtained solutions to the above definition. Iteration is needed if the estimate of $t_{\mathrm{m}}$ does not meet the requirements of this definition. Application of this procedure to a field data set is presented in more detail below. Combining Eq. [3] and [10], and assuming $\partial H / \partial z=-1$ gives

$$
-\alpha z \frac{\mathrm{d} p}{\mathrm{~d} t}=K_{\mathrm{sm}} \frac{p}{p_{\mathrm{m}}} .
$$

Intcgrating Eq. [11] from $p_{m}$ to $p$ and from 0 to $t$ gives

$$
p=p_{\mathrm{m}} \exp \left(-\frac{K_{\mathrm{sm}}}{\alpha z p_{\mathrm{m}}} t\right)
$$

When an initial estimate of $p_{m}$ for a known $\theta_{\mathrm{sh}}$ is chosen, Eq. [12] can be used to fit the data of $p=\theta-\theta_{\mathrm{sh}}$ against time to obtain a new value of $p_{m}$. If the initial value of $p_{m}$ is different from the new value obtained by fitting, let the new $p_{m}$ be the initial value and repeat the above process until the new value is the same as, or close enough to, the initial one, which would be the final result of $p_{m}$. Then the saturated hydraulic conductivity for the macropore, $K_{\mathrm{sm}}$, can be obtained from Eq. [12] as well.

\section{The Matrix Domain}

After macropores have drained, only matrix flow remains. The gravitational matrix flow is assumed to maintain unit hydraulic gradient. For this case, with Campbell's formula for the matrix hydraulic conductivity, Eq. [2], Eq. [10] can be expressed as

$$
-\alpha z \frac{\mathrm{d} \theta}{\mathrm{d} t}=K_{\mathrm{sh}}\left(\frac{\theta}{\theta_{\mathrm{sh}}}\right)^{2 b+3}
$$

Equation [13] can be solved by rearranging and integrating:

$$
\begin{gathered}
-\alpha z \int_{\theta_{\mathrm{sh}}}^{\theta} \frac{\mathrm{d} \theta}{\left(\theta / \theta_{\mathrm{sh}}\right)^{2 b+3}}=\int_{0}^{t} K_{\mathrm{sh}} \mathrm{d} t \\
(2 b+2) \ln \left(\frac{\theta_{\mathrm{sh}}}{\theta}\right)=\ln \left[1+\frac{K_{\mathrm{sh}} t(2 b+2)}{\theta_{\mathrm{sh}} \alpha z}\right] .
\end{gathered}
$$

At sufficiently long time $\left(t \geq t_{\mathrm{h}}=\left(\theta_{\mathrm{sh}} \alpha z\right) /\left[K_{\mathrm{sh}}(2 b+2)\right]>\right.$ 1], where $t_{h}$ is a critical time to calculate $K_{s h}$ and is determined by iteration, we can obtain further simplification:

$$
\begin{gathered}
(2 b+2) \ln \left(\frac{\theta_{\mathrm{sh}}}{\theta}\right)=\ln \frac{K_{\mathrm{sh}} t(2 b+2)}{\theta_{\mathrm{sh}} \alpha z} \\
\ln \left(\frac{\theta_{\mathrm{sh}}}{\theta}\right)=\frac{1}{2 b+2} \ln t \\
+\frac{1}{2 b+2} \ln \frac{K_{\mathrm{sh}}(2 b+2)}{\theta_{\mathrm{sh}} \alpha z}
\end{gathered}
$$

Plotting $\ln \left(\theta_{\mathrm{sw}} / \theta\right)$ against $\ln (t)$ and fitting Eq. $\mathrm{p}[17]$ provides an opportunity to estimate the coefficients $b$ and $K_{\mathrm{sh}}$ in Eq. [2] for the matrix hydraulic conductivity.

\section{Application}

The application of the above-mentioned approach for obtaining hydraulic parameters of macropore soils requires special flow situations in the profile: initial saturation and free drainage. In situ measurements of $\theta(z, t)$ and bulk density values of soil samples at each depth are necessary for the analysis. The proposed method is applied as follows:

1. The total saturated water content $\left(\theta_{s}\right)$ is estimated either from field measurement or from $1-\left(\rho_{b} / \rho_{p}\right)$ for a given $\rho_{b}$ and $\rho_{\mathrm{p}}$.

2. The plot of $\ln (\theta)$ vs. $\ln (t)$ determines whether macropore flow was present under the conditions of the measurement. When two-domain flow behavior exists, the plot evidences a two-piece relationship of $\ln [\theta(t)]$ given the above assumptions. The breakpoint at the intersection of the two-piece relationship, however, does not represent a transition point separating the drainage stages of two domains. As described above, there are primarily three drainage stages under the proposed conditions, and those data involving mixed flow from both domains are not suitable for the analyses of either macropore or matrix domain. Iteration is usually needed to obtain solutions. By inspection, a group of early time measurements, the last point 
of which refers to $t_{m}$, is chosen for the analysis of the macropore domain. A group of points at the later time, the first point of which refers to $t_{\mathrm{h}}$, is used for the matrix analysis. We emphasize that $t_{\mathrm{m}} \neq t_{\mathrm{n}}$. In addition, $t_{\mathrm{h}}$ has to meet with the critical time for using $\mathrm{Eq}$. [17] in Step 5 below.

3. Values of $\theta^{*}=\alpha \theta_{\varepsilon}+\beta$ are obtained by the regression of $\theta^{*}$ vs. $\theta_{z}$ during the drainage process, from which the coefficient $\alpha$ results. Each depth may have a separate relationship. However, all relationships of $\theta^{*}$ and $\theta_{z}$ for different depths are approximately parallel, and have the same $\alpha$. Since the coefficient $\beta$ is eliminated by the differentiation of Eq. $[10]$ and only $\alpha$ is useful, the relationship of $\theta^{*}\left(\theta_{2}\right)$ for the whole profile can be applied for all ths.

4. The values of $p t=\theta(t)-\theta_{s h}^{\prime}$ from the group of data for the macropore doi. in are approximated from an initial estimate of the total macroporosity $\left(p_{m}^{\prime}\right)$, from which the initial matrix saturated water content $\theta_{\mathrm{sh}}^{\prime}=\theta_{\mathrm{s}}-p_{\mathrm{m}}^{\prime}$ can be determined. A new value of the macroporosity $\left(p_{m}\right)$, as well as the macropore saturated hydraulic conductivity $\left(K_{\mathrm{sm}}\right)$, is calculated using the regression of Eq. [12] for the macropore domain. If $p_{m} \neq p_{m}^{\prime}$, let $p_{m}^{\prime}=p_{m}$ and then repeat the above process until the two values converge. Determine the final values of $p_{m}$, $\theta_{\mathrm{sh}}$, and $K_{\mathrm{sm}}$ with the iteration and regression of Eq. [12]. If the iteration of $p_{m}$ using Eq. [12] does not converge, which may occur when macroprorsity is quite small, choose a final estimate of $p_{m}$, based on a reasonable value of $K_{\mathrm{sm}}$ calculated by Eq. [12] with sufficiently high correlation coefficient.

5 . For the group of data when $t \geq t_{n}$, estimation of $b$ and $K_{\mathrm{sh}}$ from Eq. [17] for the matrix domain may require iteration to satisfy the time criterion: $t \geq t_{\mathrm{h}}=\left(\theta_{\mathrm{sh}} \alpha z\right) /\left[K_{\mathrm{sh}}(2 b+2)\right]>$ 1.

6. The obtained solutions for both domains after the steps below can be used to calculate the time when macropores are empty and the matrix starts draining, respectively. If the time when macropores are empty is earlier than $t_{n}$, and the time when the matrix starts draining is later than $t_{m}$, then the obtained solutions are final; otherwise, repeat the above steps by choosing different groups of data points until the above conditions are met.

\section{EXAMPLES AND DISCUSSION}

The method proposed above has been tested for $\theta(z, t)$ measurements of Wahiawa soils at the Poamoho site obtained by Green et al. (1982). Field experiments were conducted at Wahiawa in central O'ahu (Hawaii) on soils classified as Oxisols. These Oxisols develop principally in residuum and old alluvium derived from basaltic rock and are primarily composed of kaolinite and the oxides of $\mathrm{Fe}$ and $\mathrm{Al}$. Although the clay content of these soils is very high, up to $90 \%$ in some cases, they are highly structured, permeable, and generally well drained. Cracks in various sizes, up to $5 \mathrm{~mm}$ in width, can be observed on the soil surface. The soil profile usually exceeds $\mathbf{1} \mathbf{~ m}$ in depth, but crop rooting is sometimes limited to the plow layer (about $45 \mathrm{~cm}$ ) due to the combination of low macroporosity in the $B$ horizon and the development of tillage pans. Data were obtained by a double-ring infiltrometer with multiple-depth tensiometers. The ring diameters were $30 \mathrm{~cm}$ for the inner ring and $120 \mathrm{~cm}$ for the outer ring. Tensiometer measurements were obtained at several depths for many times during the drainage process after steady infiltration. Subsequently, three or more undisturbed soil cores, $10 \mathrm{~cm}$ in diameter and 7.5 $\mathrm{cm}$ long, were taken at each of the depths, 20, 30, 60, and $90 \mathrm{~cm}$, where water characteristics curves and bulk density were measured. Soil $\rho_{\mathrm{b}}$ is $1.078 \mathrm{~g} \mathrm{~cm}^{-3}$ from the surface down to $30 \mathrm{~cm}$ and $1.304 \mathrm{~g} \mathrm{~cm}^{-3}$ from 60 down to $90 \mathrm{~cm}$; there is a transition of bulk density between the 30- and 60-dm depths. The total soil saturated water content was estimated for a given soil $\rho_{h}, 2.65 \mathrm{~g} \mathrm{~cm}^{-3}$. Soil water contents with time at each depth were calculated from field tensiometer readings and core water retention data (Green et al., 1982).

Given the above, calculation of hydraulic parameters for both matrix and macropore domains is possible. For example, the soil bulk density is $1.078 \mathrm{~g} \mathrm{~cm}^{-3}$ at the $20-\mathrm{cm}$ depth, and the total soil $\theta_{s}$ is, as described above, 0.593 . The in situ $\theta$ measured at the $20-\mathrm{cm}$ depth was recorded at $t=0,29 \mathrm{~min}, 37 \mathrm{~min}, .$. , to $8448 \mathrm{~min}$. Based on the assumptions and the linear relationship between $\ln (\theta)$ and $\ln (t)$ for the matrix, it is clear (Fig. 1) that early and later infiltration do not tend to follow a single straight line, suggesting the flow features of a twodomain system.

Coefficients $\alpha$ and $\beta$ in Eq. [9] can be obtained by using measurements of water content with depth and curvefitting of plots (Fig. 2), which gives, for example at $z$ $=20 \mathrm{~cm}, \alpha=0.548$ and $\beta=0.241$ for the Wahiawa soils.

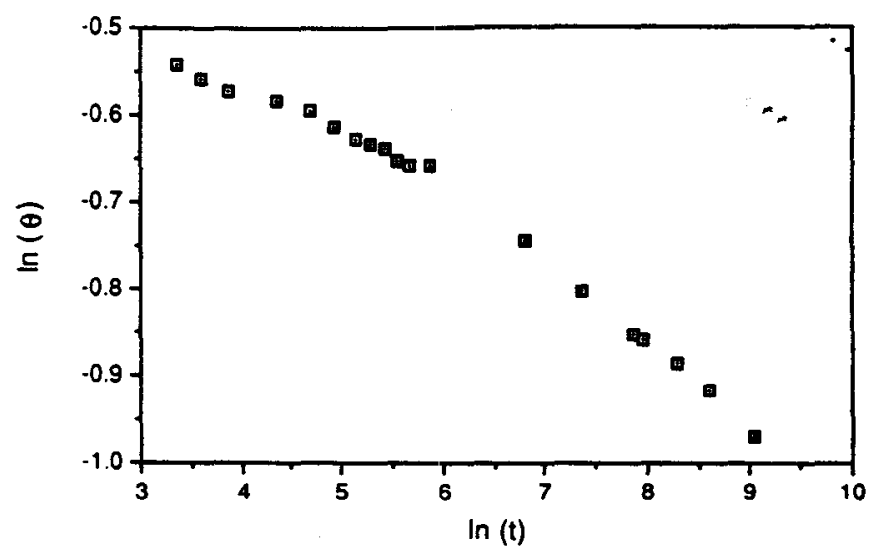

Fig. 1. Relationship between logarithm of time $[\ln (t)]$ and logarithm of water content $[\operatorname{In}(\theta)]$ for the Wahiawa soil at the $20-\mathrm{cm}$ depth.

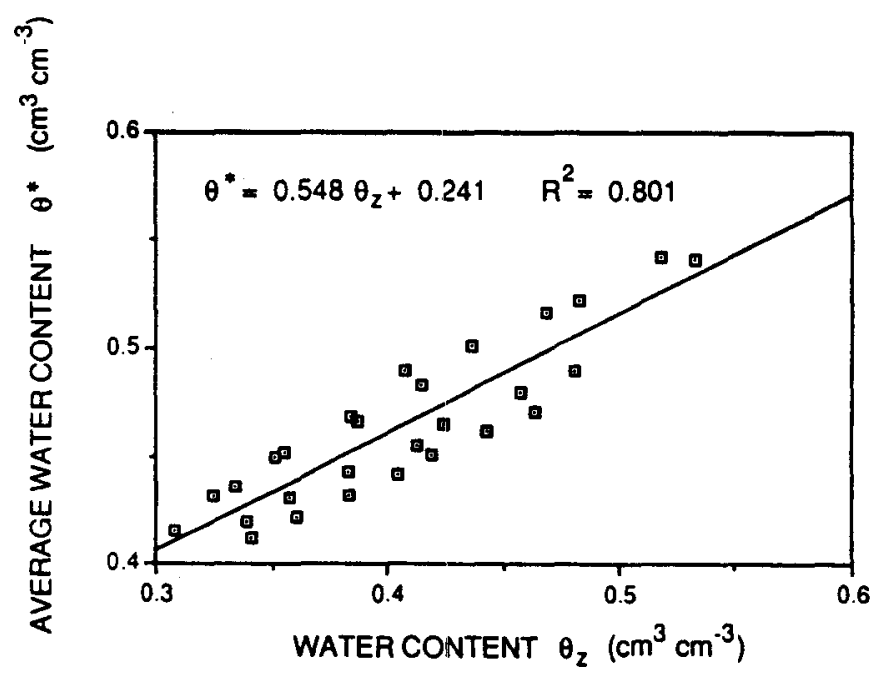

Fig. 2. Relationship between average water content $\left(\theta^{*}\right)$ and water content $(\theta$,$) at depth z$. 


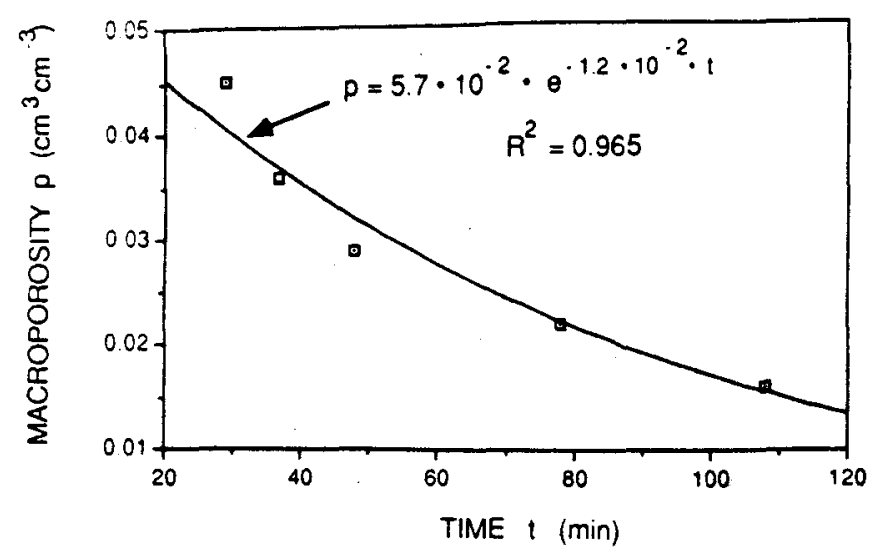

Fig. 3. Regression of water-nilled volume of macroporosity $(p)$ vs. time $(t)$ for the macropore domain.

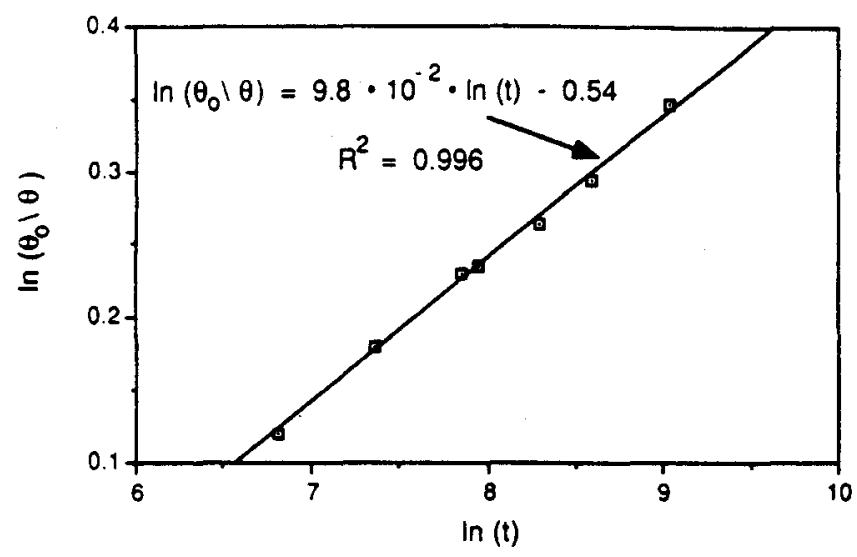

Fig. 4. Regression of logarithm of water content $[\ln (\theta)]$ vs. logarithm of time $[\ln (t)]$ for the matrix domain.

From inspection of Fig. 1, measurements of $\theta(z, t)$ when $t \leq t_{\mathrm{m}}=108 \mathrm{~min}$ were used for the estimation of the hydraulically effective macroporosity $\left(\boldsymbol{p}_{\mathrm{m}}\right)$ and the saturated hydraulic conductivity $\left(K_{\mathrm{sm}}\right)$ of the macropore domain. Figure 3 illustrates the results after the iterative regression with Eq. [12]. Thus, values of $p_{\mathrm{m}}=0.057$, $K_{\mathrm{sm}}=110.0 \mathrm{~mm} \mathrm{~d}-1$, and $\theta_{\mathrm{sh}}=0.536$, with correlation coefficient $R^{2}=0.965$, are obtained.

For the matrix domain, iteration started with those data when $t \geq t_{\mathrm{h}}=908 \mathrm{~min}$, and Eq. [17] was applied to estimate the saturated hydraulic conductivity $\left(K_{\mathrm{sh}}\right)$ and coefficient $b$ of the matrix domain. Figure 4 illustrates the result of curve-fitting for the matrix domain. Applying Eq. [17], we obtained $b=4.10$ and $K_{\text {sh }}=32.0$ $\mathrm{mm} \mathrm{d}^{-1}$ for Campbell's equation. The above calculations indicate that their accuracy is highly dependent on the sensitivity and accuracy of the $\theta(z, t)$ measurements.

For the calculated coefficients, Eq. [17] calculates $t$ $=693$ min when the matrix began to drain, which is bigger than $t_{\mathrm{m}}=108 \mathrm{~min}$. Those values used for the macropore calculation did not encounter the drainage stage from the matrix domain. Given the calculated parameters, $99 \%$, the most, of macropores are empty by using Eq. [12] when $t=384$ min, which is smaller than $t_{\mathrm{h}}=$ $908 \mathrm{~min}$. The above calculation for the matrix domain was not influenced by the drainage of macropores. Those
Table 1. Calculated soil and hydraulic parameters of Wahiawa soil obtained by the proposed two-domain method.

\begin{tabular}{|c|c|c|c|c|c|c|c|}
\hline \multirow[b]{2}{*}{ Depth } & \multirow[b]{2}{*}{$\begin{array}{c}\text { Bulk } \\
\text { density }\end{array}$} & \multirow{2}{*}{$\begin{array}{l}\text { Total } \\
\text { macro- } \\
\text { porosity }\end{array}$} & \multirow[b]{2}{*}{$b \boldsymbol{t}$} & \multicolumn{2}{|c|}{$\begin{array}{c}\text { Saturated } \\
\text { hydraulic } \\
\text { conductivity }\end{array}$} & \multirow[b]{2}{*}{$t_{n} \neq$} & \multirow[b]{2}{*}{$t_{m} \xi$} \\
\hline & & & & matrix & $\begin{array}{c}\text { macro- } \\
\text { pores }\end{array}$ & & \\
\hline $\mathrm{cm}$ & $8 \mathrm{~cm}^{-3}$ & & & \multicolumn{2}{|c|}{$-m \mathrm{~m} \mathrm{~d}^{-1}-$} & \multicolumn{2}{|c|}{$-\min -$} \\
\hline $\begin{array}{l}20 \\
30 \\
60 \\
90\end{array}$ & $\begin{array}{l}1.078 \\
1.078 \\
1.304 \\
1.304\end{array}$ & $\begin{array}{l}0.057 \\
0.009 \\
0.013 \\
0.003\end{array}$ & $\begin{array}{r}4.10 \\
4.42 \\
12.84 \\
16.33\end{array}$ & $\begin{array}{l}32.0 \\
41.4 \\
20.1 \\
64.46\end{array}$ & $\begin{array}{r}110.0 \\
21.6 \\
29.7 \\
9.7\end{array}$ & $\begin{array}{r}908 \\
1563 \\
908 \\
908\end{array}$ & $\begin{array}{l}108 \\
108 \\
198 \\
108\end{array}$ \\
\hline
\end{tabular}

$\dagger b$, a constant in Campbell's equation.

$\ddagger t_{m}$ a critical time to calculate matrix saturated hydraulic conductivity $\left(\boldsymbol{K}_{\mathrm{N}}\right)$ and is determined by iteration.

$\delta t_{m}$ a data breakpoint within the drainage stage of macropore now only (i.e., before matrix drainage starts).

Table 2. Comparisons of values calculated by the proposed method with the core and instantaneous profile measurements reported by Green et al. (1982).

\begin{tabular}{|c|c|c|c|c|c|}
\hline \multirow[b]{2}{*}{ Depth } & \multicolumn{2}{|c|}{$\begin{array}{l}\text { Total } \\
\text { macroporosity }\end{array}$} & \multicolumn{3}{|c|}{$\begin{array}{c}\text { Seturated } \\
\text { hydraulic conductivity }\end{array}$} \\
\hline & Measured $\dagger$ & Calculated $\ddagger$ & Measured $\dagger$ & $\begin{array}{l}\text { Instan- } \\
\text { taneous } \$\end{array}$ & Calculated $\neq$ \\
\hline $\mathrm{cm}$ & $-\mathrm{cm}^{3}$ & $a^{-3}$ & & $\mathrm{~mm} \mathrm{~d}^{-1}$ & . \\
\hline $\begin{array}{l}20 \\
30 \\
60 \\
90\end{array}$ & $\begin{array}{l}0.053 \\
0.065 \\
0.011 \\
0.003\end{array}$ & $\begin{array}{l}0.057 \\
0.009 \\
0.013 \\
0.003\end{array}$ & $\begin{array}{l}1928.4 \\
691.0 \\
\text { NA9 } \\
\text { NA9 }\end{array}$ & $\begin{array}{l}162.7 \\
256.3 \\
125.7 \\
108.4\end{array}$ & $\begin{array}{r}142.0 \\
63.0 \\
49.9 \\
74.2\end{array}$ \\
\hline
\end{tabular}

t Averaged values of three core-sample measurements.

† Calculated value by the proposed method.

Instantaneous profile measurements (Green et al., 1982).

I Data unvailable.

data between $384 \leq t \leq 693 \mathrm{~min}$ are of the mixed flow from both domains.

The value of $K_{\mathrm{sm}}$ at the $20-\mathrm{cm}$ depth is apparently one order of magnitude larger than that of $K_{\mathrm{sh}}$. In addition, the total soil saturated hydraulic conductivity at the 20 $\mathrm{cm}$ depth should be: $K_{\mathrm{s}}=K_{\mathrm{sm}}+K_{\mathrm{sh}}=142.00 \mathrm{~mm}$ $\mathrm{d}^{-1}$. Following the same steps, this approach can also be applied to $\theta(z, t)$ data at depths of 30,60 , and $90 \mathrm{~cm}$ in the experiments of Green et al. (1982). Results are presented in Table 1.

All parameters presented in Table 1 vary with depth. In general, observation, theory, and calculated results suggest that the surface layer maintains more macropores than greater depths because of the greater impact at the surface of temperature variation, precipitation and evaporation, biological activity, and human disturbance. The $K_{\mathrm{sm}}$ value at the $20-\mathrm{cm}$ depth is greater than $K_{\mathrm{sh}}$, and decreases with depth except around $30 \mathrm{~cm}$. The relatively smaller values of $p_{\mathrm{m}}$ and $K_{\mathrm{sm}}$ at $30 \mathrm{~cm}$ indicate the likely influence of a tillage pan on the measurement (Table 1). The total saturated hydraulic conductivity (Table 2), however, indicates that the soil profile is well drained, which agrees with the proposed assumption and conditions. In addition, based on our assumptions, the macropore parameters obtained by the proposed method are hydraulically effective and significant rather than being defined by pore size and soil structure.

Green et al. (1982) also reported laboratory measure- 


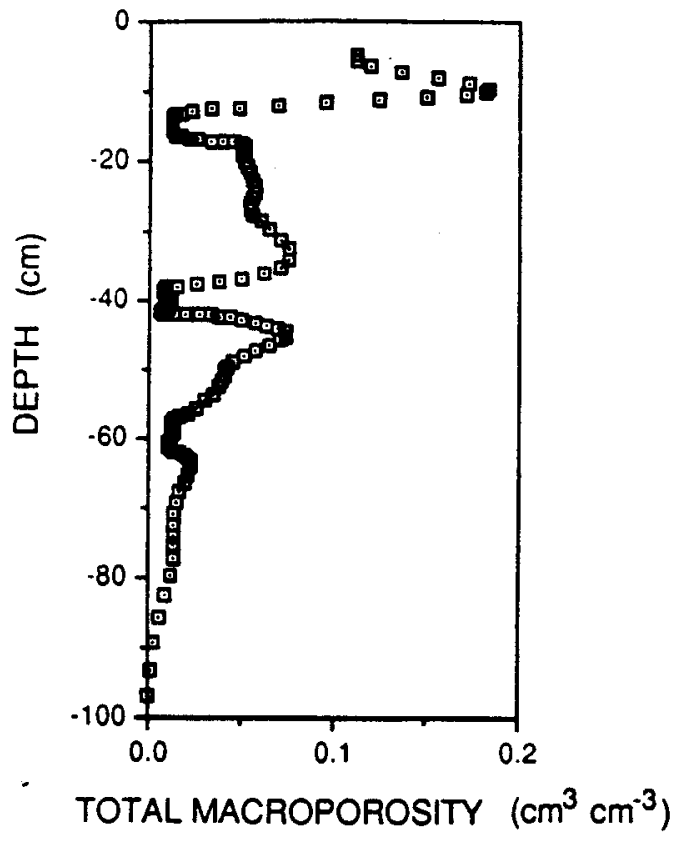

Fig. 5. Total macroporosity of averaged and smoothed core measurements of Wahiawa soil on the profile.

ments of the macroporosity (at low tension head of 50 $\mathrm{cm}$ of water) and the total soil saturated hydraulic conductivity from the three core samples collected at each depth. Figure 5 illustrates the total averaged macroporosity of the core measurements with depth. Table 2 illustrates comparisons of the $p_{\mathrm{m}}$ and $K_{\mathrm{s}}$ values by the proposed method with the averaged values of core measurements. Macroporosity values from the proposed method and core measurements are quite close, except at the 30-cm depth, whereas values of the total soil saturated hydraulic conductivity between the proposed method and the instantaneous profile method are different. Further conclusions, however, cannot be made until more comparisons are developed through further experiments. Available $K_{\mathrm{s}}$ values of core measurements (Table 2) can be used only as a reference as reported by Green et al. (1982).

In addition, some field measurements of water infiltration on Lahaina silty clay soils and Molokai silty clay loam soils in Hawaii (Green et al., 1982) have also been tested with the above approach and exhibired characteristics of two water-flow domains. Both soils are classified as Oxisols as well. The Lahaina and Molokai series belong to the Typic Torrox great group while the Wahiawa series is a Tropeptic Eutrustox. Plotting $\ln (\theta)$ vs. $\ln (t)$ from field measurements on Norfolk loamy sand soils (a member of the Typic Paleudults) in the southern region of the USA by Quisenberry et al. (1987) also indicates similar evidence of two-domain flow behaviors (like Fig. 1, an apparent two-piece relationship exists). From the modeling point of view, variation of $K_{\mathrm{sm}}$ and macroporosity in the profile makes description, simulation, and prediction of water movement more difficult, but a more sophisticated model using the two-domain conceptualization may permit application of the technique presented here.

\section{CONCLUSIONS}

There are two ways to characterize macropore soils. The proposed method recommends emphasis on the hydraulic effectiveness and significance of macropores in two-domain flow systems rather than focusing on pore size and soil structure. We presented a step-by-step method to characterize the useful hydraulic parameters of both macropore and matrix domains based on the two-domain flow system. The method requires only $\theta(z, t)$ measurements under free-drainage conditions for the initially saturated profile. The examples have shown that the method is simple and applicable in practice. Accuracy of results, however, is highly dependent on the sensitivity and accuracy of the $\theta(z, t)$ measurements.

\section{ACKNOWLEDGMENTS}

Deep appreciation goes to Drs. C. McVoy and D. Swaney for their constructive suggestions and comments on this study.

\section{REFERENCES}

Addiscott, T.M., D.A. Rose, and J. Bolton. 1978. Chloride leaching in the Rothamsted drain gauges: Influence of rainfall pattern and soil structure. J. Soil Sci. 29:305-314.

Beven, K., and P. Germann. 1982. Macropores and water flow in soils. Water Resour. Res. 18:1311-1325.

Bouma, J., A. Jongerius, and D. Schoonderbeek. 1979. Calculation of saturated hydraulic conductivity of soil pedal clay soils using micromorphometric data. Soil Sci. Soc. Am. J. 43:261264.

Campbell, G.S.A. 1974. A simple method for determining unsaturated conductivity from moisture retention data. J, Soil. Sci. 117:311-314.

Chen, C., and R.J. Wagenet. 1992a. Simulation of water and chemicals in macropore soils: 1. Representation of the equivalent macropore influence and its effecton soil-water flow. J. Hydrol. (Amsterdam) 130:105-126.

Chen, C., and R.J. Wagenet. 1992b. Simulation of water and chemicals in macropore soils: 2. Application of linear filter theory to description of transport. J. Hydrol. (Amsterdam) 130:127-149.

Germann, P.F., and K. Beven. 1985. Kinematic wave approximation to infiltration into soils with sorbing macropores. Water Resour. Res. 21:990-996.

Green, R.E., and L.R. Ahuja, S.K. Chong, and L.S. Lau. 1982. Water conduction in Hawaii oxic soils. Univ. of Hawaii Water Resources Research Center Tech. Rep. 143. Univ. of Hawaii at Manoa, Honolulu.

Hall, D.G.M., M.J. Reeve, A.J. Thomasson, and V.F. Wright. 1977. Water retention, porosity and density of field soils. Soil Surv. Engl. Wales Tech. Monogr. no. 9. SSEW, Harpenden, UK.

Hoogmoed, W.B., and J. Bouma. 1980. A simulation model for predicting infiltration into cracked clay soil. Soil Sci. Soc. Am. j. 44:458-461.

Jury, W.A. 1982. Simulation of solute transport using a transfer function model. Water Resciur. Res. 18:363-368.

Jury, W.A., L.A. Stolzy, and P. Shouse. 1989. A field test of the transfer function model for predicting solute transport. Water Resour. Res. 18:369-375.

Libardi, P.L., K. Reichardt, D.R. Nielsen, and J.W. Biggar. 1980. Simple field method for estimating soil hydraulic conductivity. Soil Sci. Soc. Am. J. 44:3-7.

Luxmoore, R.J. 1981 . Micro-, meso- and macroporosity of soil. Soil Sci. Soc. Am. J. 45:671.

Quisenberry, V.L., D.K. Cassel, J.H. Dane, and J.C. Parker. 1987. Physical characteristics of soils of the southern region Norfolk, Dothan, Wagram, and Goldsboro series. South Carolina Agric. Exp. Stn., Clemson Univ., Clemson, SC.

Steenhuis, T.S., and J.-Y. Parlange. 1988. Simulating preferential flow of water and solutes on hillslopes. p. $1-10$. In P.J. Wierenga and $D$. Bachelet (ed.) Validation of flow and transport models for the unsaturated zone. Proc. Int. Conf. Worksh., Ruidoso, NM. 23-26 May 1988. New Mexico State Univ., Las Cruces.

Steenhuis, T.S., J.-Y. Parlanige, and M.B. Parlange. 1987. A simple model for preferential flow on hillslopes. p. 16.1-17. Proc. Symp. 36 Agrohydrcl., 29 Sept-1 Oct., Dep. of Land 
and Water Use, Agriculture Univ., Wageningen, the Netherlands.

van Genuchten, M. Th., and P.J. Wierenga. 1976. Mass transfer studies in sorbing porous media: I. Analytical solutions. Soil Sci. Soc. Am. J. 40:473-480.

White, R.E. 1985a. A model for nitrate leaching in undisturbed structured clay soil during unsteady flow. J. Hydrol. (Amsterdam) 79:37-51.

White, R.E. 1985b. The influence of macropores on the transport of dissolved and suspended matter through soil. Adv. Soil Sci. 3:95-120. 